\title{
Analisis Forensik pada Web Phishing Menggunakan Metode National Institute Of Standards And Technology (NIST)
}

\author{
Agil Nofiyan a,1,*, Mushlihudin ${ }^{\mathrm{b}, 2}$ \\ a b Program Studi Teknik Informatika, Fakultas Teknologi Industri, Universitas Ahmad Dahlan, Jalan Ringroad Selatan, \\ Kragilan, Tamanan, Kec. Banguntapan, Bantul, Daerah Istimewa Yogyakarta (55191), Indonesia \\ ${ }^{1}$ agil1500018271@webamil.uad.ac.id *; ${ }^{2}$ mushlihudin@ tif.uad.ac.id ${ }^{3}$ \\ * Penulis Korespondensi
}

\section{ABSTRAK}

Komunikasi dan informasi menjadi kebutuhan yang sangat penting dan dapat menimbulkan masalah pada teknologi itu sendiri. Bentuk kejahatan cybercrime dengan teknik phishing, phiser memanipulasi link atau URL yang sengaja dilakukan untuk mendapatkan informasi penting dari seseorang atau kelompok. Teknik tersebut dengan menyisipkan script atau memanipulasi website dengan protocols HTTPS (Hypertext Transfer Protocol Secure) pada website yang digunakan oleh phiser. Hal tersebut untuk menarik perhatian korban mengakses URL atau situs yang phiser sebarkan melalui email. Maraknya pencurian account berbasis web phishing yang digunakan phiser atau pelaku dengan tujuan mengambil data yang sensitive pada account korban seperti username dan password.

Penggunaan metode National Institute of Standards and Technology (NIST) bertujuan untuk menganalisis proses investigasi atau forensik digital kasus cybercrime dan memunculkan barang bukti digital. Tahapan analisis berupa Collection, Examination, Analysis dan Reporting. Penggunaan tools wireshark untuk mencari barang bukti dan tools hashcalc untuk mengakuisisi barang bukti yang didapatkan. Hasil barang bukti digital tersebut dapat digunakan untuk proses penyelidikan mengungkap kejahatan digital.

Penelitian ini menganalisis serangan web phishing oleh phiser menggunakan fitur fake login dan didapatkan file capture wireshark dari web phishing dengan protocols HTTPS serta hasil analisis dari pendekripsian pada keamanan yang terdapat pada protocols HTTPS berupa URL phishing, DNS (Domain Name System) yang digunakan oleh pelaku, IP address server, IP address destination, identitas penyerang dan email dari informasi tindak kejahatan yang dilakukan phiser untuk mendapatkan account valid milik korbannya.

Kata Kunci : Web Pishing, digital forensik, cybercrime, fake login, wireshark

\section{Pendahuluan}

Perkembangan teknologi yang semakin pesat, dapat menimbulkan permasalahan bagi teknologi itu sendiri, hal tersebut menjadikan internet sebagai salah satu media yang dimanfaatkan untuk pencurian data oraganisasi, individu maupun pemerintahan. Cybercrime berdasarkan jenis aktivitas seperti Unauthorized Acces kejahatan yang dilakukan seseorang dengan memasuki sistem jaringan komputer tanpa izin dari pemilik sistem jaringan komputer yang dimasukinya, Ilegal Contens kejahatan dengan memasukan data atau informasi ke internet dan dianggap melanggar hukum, Penyebaran virus dengan sengaja seperti Malware dengan merusak software. Carding kejahatan untuk mencuri nomor kredit milik orang lain dan digunakan dalam transaksi perdangangan di internet [1]. Dalam hal ini phishing dikenal juga sebagai carding yaitu sebuah bentuk layanan menipu dengan menjanjikan keabsahan dan keamanan transfer data yang dilakukan. Penanganan pada kasus cybercrime tidak bisa hanya menggunakan bukti screenshoot, foto, maupun video karena bisa saja dapat dimanipulasi oleh pihak terkait, pada penelitian ini membutuhkan bukti lengkap terkait bukti digital seperti link atau URL, Email, Domain, IP address, dan identitas pelaku yang digunakan pelaku untuk memancing korban. Proses menemukan dan mengidentifikasi barang bukti digital membutuhkan proses yang panjang dan membutuhkan waktu untuk memperoleh data yang akurat [2]. Keamanan menjadi hal yang utama dalam perkembangan teknologi informasi dan dunia forensik, dengan perkembangan teknologi secara pesat berdampak pada kejahatan cybercrime. Namun bentuk kejahatan cybercrime dengan teknik phishing, phiser memanipulasi link atau URL yang sengaja 
dilakukan untuk mendapatkan informasi penting dari seseorang atau kelompok. Teknik tersebut dengan menyisipkan script atau memanipulasi sebuah web dengan protocols HTTPS pada website yang digunakan oleh phiser. Hal tersebut untuk menarik perhatian korban mengakses URL atau situs yang phiser sebarkan melalui email. Protocols HTTPS mempunyai keamanan yang tinggi dengan cara mengenkripsi data menggunakan algortihma dari hal ini phiser memanfaatkan keamanan HTTPS untuk membuat web phishing dan juga meyakinkan korban bahwa web tersebut aman untuk digunakan. Pencurian account berbasis web phishing dengan fake domain yang digunakan phiser atau pelaku, dengan tujuan mengambil data yang sensitive pada account korban seperti username dan password. Oleh karena itu, pada penelitian ini ini peneliti membuat skenario kasus kejahatan web phishing dengan memanfaatkan fitur login dan fake domain bertujuan untuk menganalisis proses investigasi atau forensik digital kasus cybercrime serta memunculkan barang bukti meliputi DNS, IP address server, IP address destination, identitas penyerang, email korban dan email pelaku. Penyelidikan menggunakan tahapan dari metode National Institute Of Standards And Technology (NIST) dengan empat tahapan sebagai acuan analisis barang bukti yaitu collection, examination, analiysis, dan reporting.

\section{Landasan Teori}

\subsection{Forensik Digital}

Forensik digital merupakan bagian dari ilmu forensik yang meliputi pemulihan dan investigasi dari bahan yang ditemukan pada perangkat digital (digital devices), komputer (host, server), jaringan (network), dan aplikasi. Forensik digital merupakan ilmu yang masih baru dan dibutuhkan pemahaman dan kemampuan untuk menguasai ilmu ini [3]. Tahapan pada digital forensik digunakan untuk menjadi acuan menangani kasus tersebut, tahapannya sebagai berikut:

1. Identifikasi

Dalam tahapan awal ini proses identifikasi pada barang bukti sangat penting untuk melakukan proses penyelidikan pada tahap berikutnya.

2. Pemeliharaan

Pemeliharaan pada barang bukti digital harus dijaga dan terhindar dari kerusakan karena barang bukti hilang atau berubah membuat barang bukti tidak akan di akui di pengadilan

3. Analisis

Tahapan ini bukti digital dilakukan pemeriksaan secara detail oleh penyidik untuk membuktikan kejahatan tersebut. Hasil analisis harus dipertanggunjawabkan didepan pengadilan dan secara keilmiahan.

4. Presentasi

Presentasi dilakukan oleh penyidik dengan menyajikan dan menguraikan hasil dari barang bukti yang sudah di analisa, sehingga barang bukti tersebut membantu proses penyidikan untuk menemukan tersangka.

\subsection{Komputer Forensik}

Komputer forensik adalah bidang yang dapat membantu dalam upaya penegakan hukum terhadap kejahatan yang berhubungan dengan komputer langsung maupun tidak langsung dengan bantuan software yang digunakan untuk investigasi terhadap barang bukti yang ditemukan. Pentingnya ahli komputer forensik untuk pencarian dan menganalisa barang bukti pada kasus kejahatan di bidang komputer (cybercrime) [4].

\subsection{Website}

Website adalah halaman informasi yang menampilkan teks, data gambar diam atau gerak, data animasi, suara, video atau gabungan dari semuanya baik yang bersifat statis maupun dinamis yang membentuk satu rangkaian bangunan yang saling terkait dimana masing-masing dihubungkan dengan jaringan- jaringan halaman (hyperlink). Jaringan tersebut disediakan melalui jalur internet sehingga bisa di akses oleh pengguna internet di seluruh dunia. [5]. HTTP dan HTTPS adalah sebuah protokol untuk meminta atau menjawab antara client dan server, client HTTP meminta dengan membuat hubungan TCP/IP ke port 80 sedangkan HTTPS meminta dengan membuat hubungan Secure Socket Layer (SSL) atau Transport Layer Security (TLS) ke port 443. Perbedaaan HTTP dan 
HTTPS terdapat pada tingkat keamananya, pada protokol HTTP data yang dikirim ke server memiliki informasi kode yang menjelaskan dari permintaan data tersebut, setelah menerima kode, server akan menjawab atau mengirim kembali kode jawaban dari data tersebut, sedangkan protokol HTTPS data yang dikirim ke server akan terenkripsi disertai kunci publik, server bisa membaca permintaan data yang dienkripsi dan mendekripsi data dengan kunci publik. HTTPS di enkripsi dan dekripsi dari data yang diminta oleh pengguna dan data dikembalikan oleh server.[6]

\subsection{Cybercrime Phishing}

Phising adalah salah satu kejahatan yang paling cepat berkembang internet. Dimana phiser mengirim situs web yang terkait atau email secara acak untuk memancing penerima untuk membocorkan informasi pribadi, email yang digunakan seperti asli dari lembaga atau perusahaan layanan yang sah [7].

\subsection{National Intitute Of Standards And Technology (NIST)}

National Intitute Of Standards And Technology (NIST) adalah badan nasional non-regulator dari bagian administrasi teknologi Amerika Serikat. Misi dari badan ini adalah untuk mendorong dan membuat pengukuran, standar, dan teknologi untuk meningkatkan produktivitas, mendukung perdangangan, dan memperbaiki kaualitas hidup semua orang. Program cybersecurity NIST berupaya memungkinkan pengembangan lebih besar dan penerapan teknologi dan metodologi keamanan yang inovatif dan praktis untuk meningkatkan kemampuan negara mengatasi tantangan keamanan komputer dan informasi saat ini dan masa depan [8]. Tahapan pada metode National Institute Of Standards And Technology (NIST) dibawah ini tahapan yang dilakukan pada metode NIST, sebagai berikut:

1. Collection (Pengumpulan data)

Pada tahapan ini yang dilakukan yaitu pengumpulan barang bukti dengan proses identifikasi, pengumpulan, pengambalian dan perekaman barang bukti.

2. Examinarion (Akuisisi data)

Pada tahap ini hasil dari pengumpulan barang bukti dilakukan pengujian agar tidak ada perubahan informasi pada barang bukti.

3. Analysis

Pada tahap ini barang bukti dilakukan pemeriksaan untuk mendapatkan bukti terkait dengan kasus tersebut.

4. Reporting (Pembuatan laporan)

Pelaporan hasil investigasi yang didapatkan dari penyelidikan berisi tentang hasil analisa barang bukti sehingga bukti tersebut membantu proses penyidikan untuk menemukan tersangaka.

\section{Metodologi}

Pada penelitian ini untuk mengungkap bukti kejahatan cybercrime dengan objek penelitian ini adalah fitur fake login yang dimanfaatkan oleh phiser untuk ekspolitasi data user dengan mendapatkan informasi username dan password korban dengan menggunakan email sebagai media penyebaran URL phishing. Metode yang digunakan untuk mengungkap kejahatan adalah National Institute Of Standards And Technology (NIST).

\subsection{Hardware dan Software yang Digunakan}

Penelitian ini dikerjakan menggunakan perangkat hardware, software dan beberapa web untuk menganalisa web phishing. Penelitian ini dilakukan dengan menggunakan 2 laptop kepemilikan yaitu milik investigator dan milik pelaku. Perangkat keras (hardware) dan perangkat lunak (software) yang digunakan investigator untuk menganalisis web phising seperti Tabel 1 sebagai berikut:

Tabel 1. Tabel Peralatan Investigator 


\begin{tabular}{|l|l|l|}
\hline \multicolumn{1}{|c|}{ Hardware } & \multicolumn{1}{c|}{ Software } & \multicolumn{1}{c|}{ Website } \\
\hline $\begin{array}{l}\text { Processor Intel® Celeron } ® \\
\text { CPU N2840 @ 2.16GHz }(2 \\
\text { CPUs), 2.16GHz }\end{array}$ & $\begin{array}{l}\text { Sistem operasi windows 10 Pro 64- } \\
\text { bit, x64 based processor }\end{array}$ & $\begin{array}{l}\text { https://centralops.net } \\
\text { (pencarian informasi tentang } \\
\text { DNS) }\end{array}$ \\
\hline Graphics Intel® HD Graphics & Wireshark-win64-3.0 & \\
\hline RAM 2GB & Hashcalc & \\
\hline Harddisk 1 TB & Mozilla Firefox 71.0(32-bit) & \\
\hline
\end{tabular}

Perangkat keras (hardware) dan perangkat lunak (software) yang digunakan pelaku untuk merekontruksi serangan web phishing seperti ditampilkan pada Tabel 2.

Tabel 2. Tabel Peralatan Pelaku

\begin{tabular}{|l|l|}
\hline \multicolumn{1}{|c|}{ Hardware } & \multicolumn{1}{c|}{ Software } \\
\hline $\begin{array}{l}\text { Processor Intel }{ }^{\circledR} \text { Core } \\
\text { @ } 2.80 \mathrm{GHz} \text { i7-7700 HQ CPU }\end{array}$ & $\begin{array}{l}\text { Sistem operasi windows 10 Pro 64-bit, x64 based } \\
\text { processor }\end{array}$ \\
\hline Graphics Intel@ HD Graphics 630 & Sublime Text 3 \\
\hline RAM 8 GB & Xampp versi 3.2.2 \\
\hline & Mozilla Firefox 71.0(64-bit) \\
\hline
\end{tabular}

\subsection{Simulasi Kasus Kejahatan Cybercrime}

Simulasi kasus kejahatan cybercrime ini bertujuan untuk menjelaskan alur kejahatan cybercime yang dilakukan phiser seperti Gambar 1.

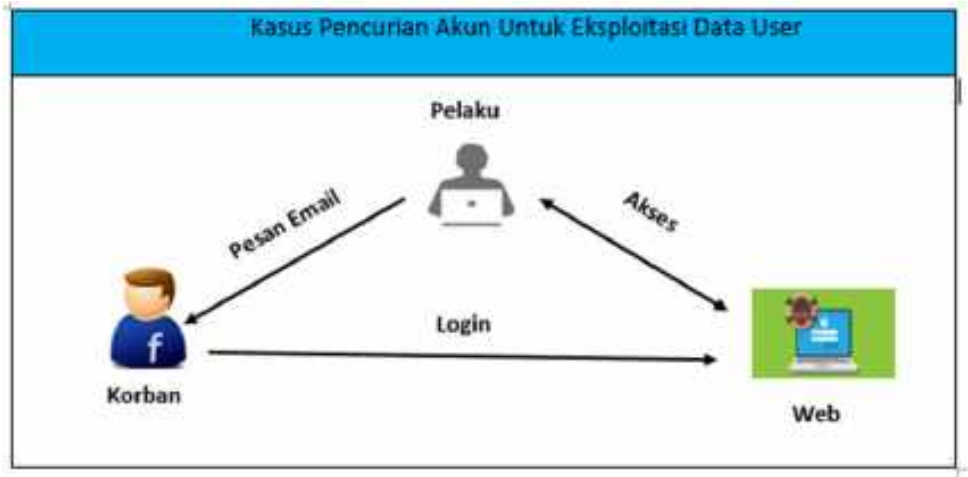

Gambar 1. Alur Proses Pencurian Akun

Pada tahapan ini akan dijelaskan alur pencurian account seperti Gambar 1 yang menjelaskan bagaimana pelaku mengirimkan email yang berisi URL phishing kemudian korban secara tidak sadar melakukan login menggunakan URL phishing tersebut, dari kejadian ini pelaku mendapatkan akses account korban. Berdasarkan simulasi kasus penulis mencoba membuktikan kejahatan tersebut, berdasarkan Gambar 2 mengimplementasikan alur lebih detail simulasi ulang kasus kejahatan dan pembuktian oleh investigator. 


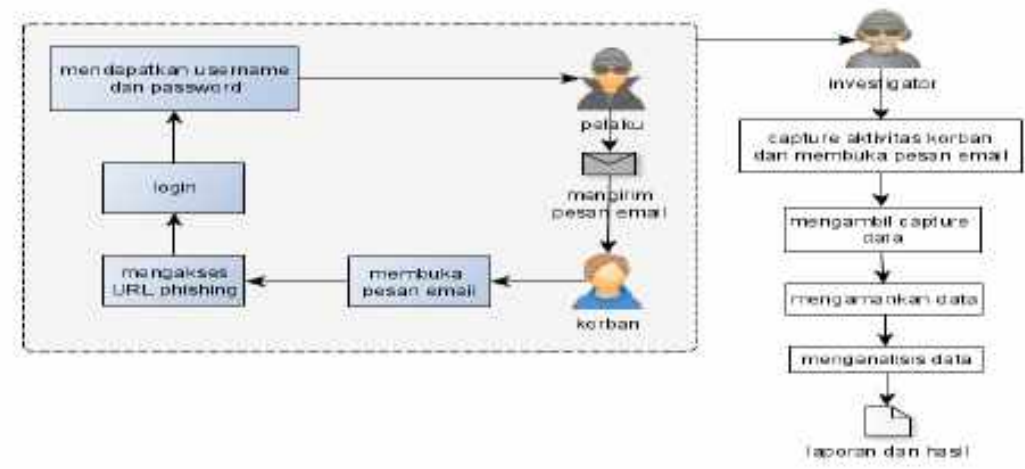

Gambar 2. Rekontruksi Kejahatan dan Pembuktian oleh Investigator

Gambar 2 menampilkan rekontruksi kejahatan dan pembuktian yang dilakukan investigator dari barang bukti awal berupa pesan email korban yang berisikan URL web phishing. Investigator melakukan capture dengan membuka pesan email, mengakses URL web phishing dan mengisi email dan password pada form fake login. Investigator melakukan capture menggunakan tools wireshark untuk mendapatkan barang bukti dari web phishing serta mengakuisisi barang bukti agar tidak ada perubahan data dari barang bukti, examination atau pemeriksaan barang bukti dengan tools hashcalc untuk menguji nilai hash dari barang bukti terjadi perubahan atau tetap sama, analisis dilakukan untuk melakukan pencarian barang bukti dari hasil capture menggunakan wireshark dan melaporkan hasil barang bukti yang didapat dengan bahasa yang mudah dipahami.

\subsection{National Institute Of Standards And Technology (NIST)}

Pada penelitian ini mengacu dengan tahapan metode National Institute Of Standards And Technology (NIST) terdiri dari 4 tahapan yang dilakukan untuk melakukan proses investigasi sebagai berikut:

\section{Collection}

Tahapan yang dilakukan pada tahap ini yaitu pengumpulan data terkait kejahatan phishing dengan proses identifikasi, pengumpulan, pengambalian dan perekaman barang bukti. Pada tahapan penelitian ini proses awal melakukan capturing paket data pada website menggunakan tools forensics wireshark, kemudian paket data dilakukan akuisisi dan disimpan untuk menghindari terjadinya perubahan informasi pada paket data.

\section{Examination}

Proses pemeriksaan barang bukti untuk yang dikumpulkan menggunakan skenario. Proses pengujian barang bukti menggunakan tool Hashcalc untuk mendapatkan informasi dari file hash sama dengan nilai file hash pada file capture.

\section{Analysis}

Proses analisis yang dilakukan investigator pada barang bukti dari hasil pengumpulan data dan akuisisi pada tahap sebelumnya untuk memperoleh barang bukti yang terkait dengan kasus tersebut. Pemeriksaan meliputi bukti DNS yang digunakan oleh pelaku, IP address server, IP address destination, identitas penyerang, email korban dan pelaku.

4. Reporting

Proses pelaporan hasil investigasi dan data yang didapatkan dari penyelidikan. Laporan berisi tentang hasil identifikasi capture data dari barang bukti URL phishing. Laporan hasil analisis meliputi gambaran yang perlu dilakukan terkait kasus tersebut.

\section{Hasil dan Pembahasan}

\subsection{Collection}

Pada tahap pengumpulan data menggunakan tools wireshark untuk mengcapture saat korban mendapatkan email dari pelaku, korban mengakses URL phishing dan korban login dengan username dan password milik korban. Pada penelitian ini peneliti mengambil file log yang tersimpan untuk membantu investigasi. Dari aktivitas korban didapatkan file hasil capture (*.pcapng) dan nilai hash 
dari file capture serta didapatkan barang bukti tambahan dari folder SSLKEY dan folder foto evidence seperti ditampilkan pada Gambar 3.

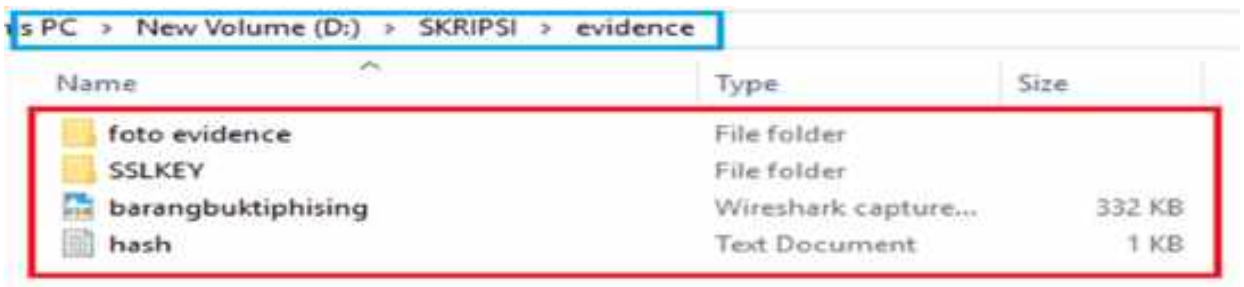

Gambar 3. Isi Folder Evidence

Gambar 3 menampilkan 1 file hasil capture (*.pcapng) yang dilakukan pada tanggal 17 November 2019 dengan file type berupa wireshark capture file, folder foto evidence yang berisi screenshoot pesan email dari pelaku dan tampilan web phishing, folder SSLKEY yang berisi file log dari web phishing yang didapatkan dari tanggal 31 Oktober - 17 November 2019 dan diperoleh juga 1 file teks (*.txt) yang dibuat pada tanggal 19 November 2019.

\subsection{Examination}

Pada penelitian ini tahap akuisisi data dilakukan secara offline menggunakan tools hashcalc didapatkan nilai hash dari setiap file barang bukti seperti Tabel 3.

Tabel 3. Nilai Hash File dari Setiap File di Folder Evidence

\begin{tabular}{|c|c|}
\hline File & Nilai Hash \\
\hline Foto 1 & 1963ceb1e523b6a085580fec7a41327c \\
\hline Foto 2 & 89de264bb94024bfa6b6ddadcfe9b744 \\
\hline Foto 3 & 7c471324ee91349ce94155e13b577255 \\
\hline Foto 4 & 139e63e9ee8106c9a713f93ab71d3d30 \\
\hline Foto 5 & 548b6db5ae8a527c9fa8f71f78df3b2a \\
\hline Barangbuktiphising.pcapng & 4b638e8f7dc62ee9a81abfcffc5678b3 \\
\hline SSLkeylog & 0862d95d7b0a13ca2c4f1bcc7b10861c \\
\hline
\end{tabular}

Tabel 3 menampilkan informasi nilai hash dari setiap file di folder evidence yang tersimpan dalam file hash.txt. Nilai hash yang dibuat menggunakan algorithma MD5 dengan tools hashcalc.

\subsection{Analysis}

Pada penelitian ini tahap analisis data barang bukti pada file capture barangbuktiphising.pcapng menggunakan tools wireshark untuk menganalisis dan mendapatkan barang bukti. File sslkeylog.log merupakan file log dari web phishing. File log ini akan membantu untuk mendekripsi pada HTTP2, TLSv1.2 dan TCP yang terenkripsi namun tidak semua data file capture yang didapat terdekripsi karena keamanan pada HTTPS menggunakan SSL (Secure Socket Layer) atau TLS (Transport Layer Security). Paket data yang akan di analisis dipilih menggunakan teknik filter untuk mempercepat dan memudahkan identifikasi paket data. Beberapa kata kunci untuk mencari paket-paket tertentu yang berhubungan dengan gmail untuk mencari pesan email, DNS dan HTTP2. Selain itu melakukan filter menggunakan kata kunci untuk mencari data secara spesifik menggunakan aplikasi wireshark misalkan, frame contains gmail dengan IP destianation 74.125.24.19 maka IP destianation dijadikan kata kunci untuk mencari data yang berhubungan dengan pesan email pada paket data nomor 148, Kata kunci DNS (Domain Name Server) yang berhubungan dengan isi pesan dari email yaitu fucebook.xyz dengan IP server 103.28.12.100 yang juga menjadi kata kunci untuk mencari barang bukti yang berhubungan dengan domain fucebook.xyz, kemudian kata kunci http2.header yang 
berhubungan dengan header dari web phishing. Tabel 4 menampilkan nomor paket data, teknik filter yang digunakan pada penelitian ini.

Tabel 4. Filterisasi yang digunakan di tools wireshark

\begin{tabular}{|l|l|l|}
\hline Paket Data & \multicolumn{1}{|c|}{ Filter } & \multicolumn{1}{c|}{ Dekripsi } \\
\hline Nomor 148 & Ip.addr $==74.125 .24 .19$ & Menunjukan trafik dari alamat IP 74.125.24.19 \\
\hline Nomor 129 & dns & Menunjukan paket dengan protokol DNS \\
\hline Nomor 132 & dns & Menunjukan paket dengan protokol DNS \\
\hline Nomor 257 & ip.addr $==103.28 .12 .100$ & Menunjukan trafik dari alamat IP 103.28.12.100 \\
\hline Nomor 259 & ip.addr $==103.28 .12 .100$ & Menunjukan trafik dari alamat IP 103.28.12.100 \\
\hline Nomor 262 & http2.header & Menunjukan paket dengan protokol http2.header \\
\hline Nomor 275 & http2.header & Menunjukan paket dengan protokol http2.header \\
\hline
\end{tabular}

Tabel 4 menampilkan filter atau kata kunci yang digunakan saat menganalisis paket data untuk mempermudah investigator saat menganalisis paket data yang tertangkap. Keterangan masingmasing nomor paket data akan dijelaskan lebih detail, meliputi:

\section{Paket Data Nomor 148}

Dari hasil analisa pada IP 74.125.24.19 merupakan capture isi pesan email URL web phishing yang dikirim pelaku kepada korban yang dikirim pada tanggal 17 November 2019, hasilnya seperti ditampilkan pada Gambar 4.

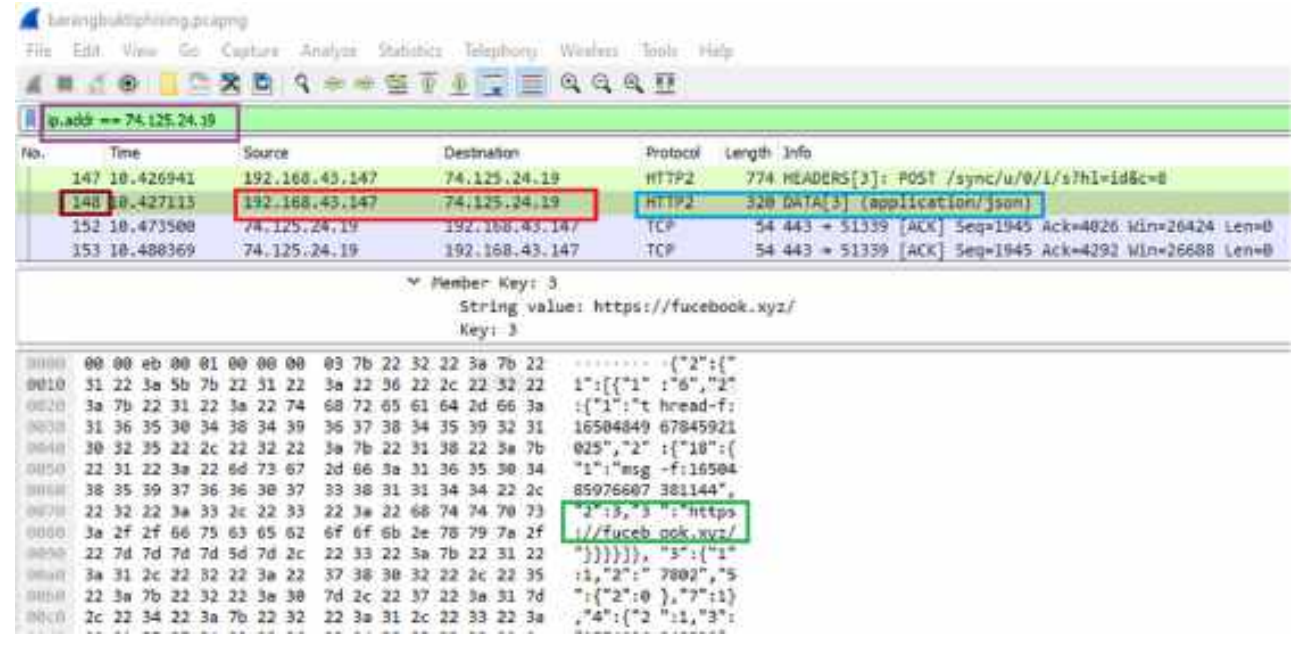

Gambar 4. Hasil Capture Isi pesan email dari paket data nomor 148

Gambar 4 menampilkan hasil capture pada paket nomor 148 dengan isi pesan email yaitu https://fucebook.xyz. Dari hasil capture pada paket nomor 148 dibandingakan dengan file screenshot foto 4 dari kotak masuk di email dindareni538@gmail.com seperti Gambar 5.

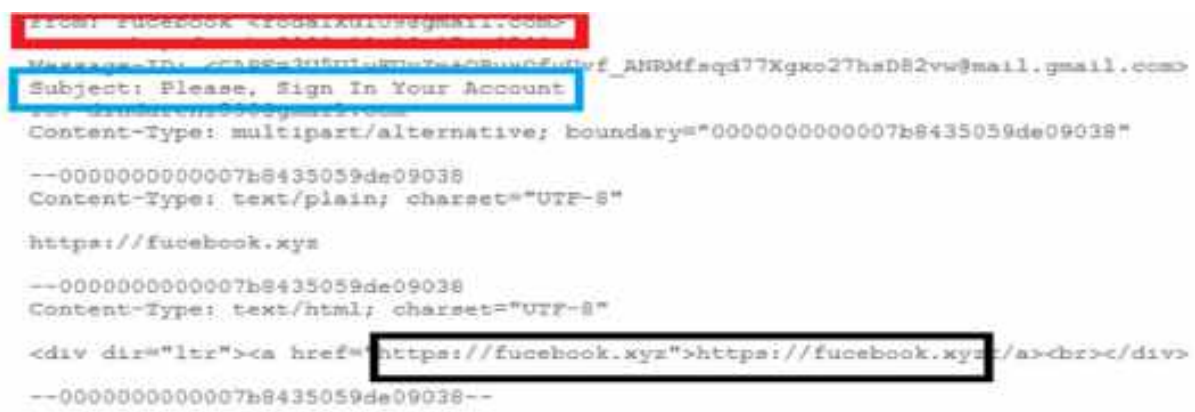

http:// http://journal.uad.ac.id/index.php/JSTIF jurnalsarjana@tif.uad.ac.id 
Gambar 5. Isi Pesan di Email dindareni538@gmail.com

Gambar 5 menunjukan isi pesan email dengan hasil capture sama yaitu https://fucebook.xyz yang merupakan URL web phishing dengan subject "Please, Sign In Your Account" dengan dalih agar korban melakukan login di URL tersebut, yang dikirimkan oleh pelaku dengan email rodalku109@gmail.com kepada korban email dindareni538@gmail.com.

\section{Paket Data Nomor 129}

Paket data nomor 129 pada analisa filterisasi DNS merupakan sebuah query request kepada DNS server yang terdapat pada paket nomor 132 yang berarti file hasil capture ketika terjadi komunikasi menggunakan protocol DNS yang digunakan oleh pelaku untuk melakukan serangan phishing. Informasi detail setiap query hasilnya seperti Gambar 6.

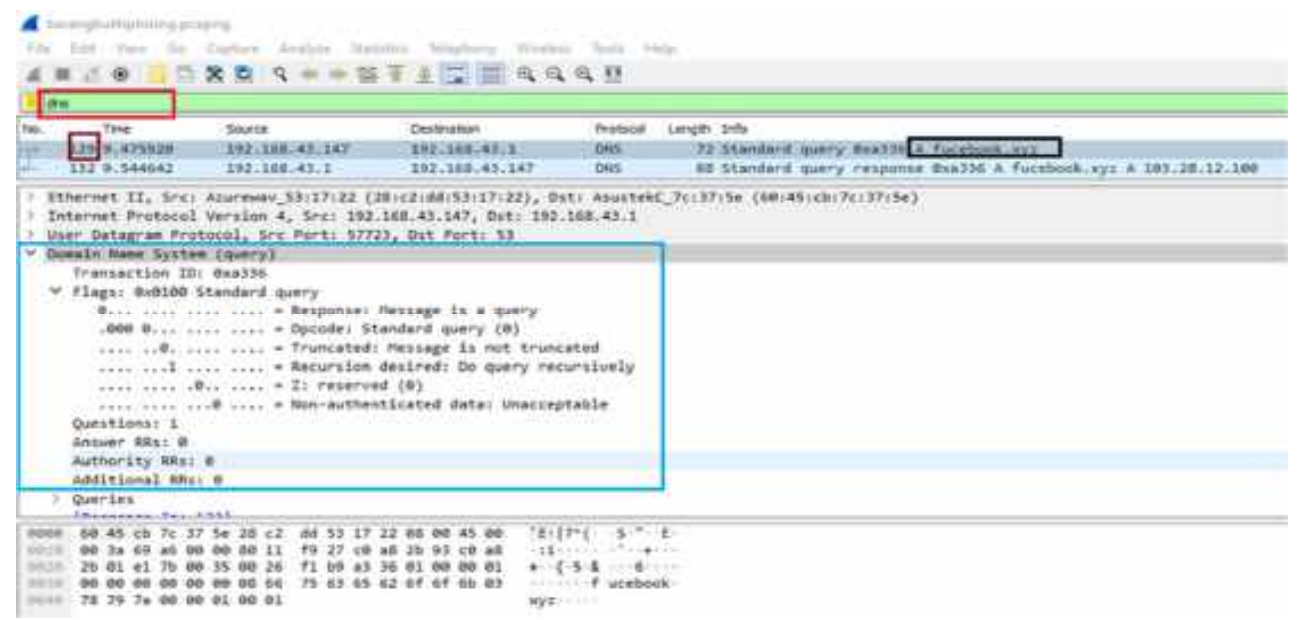

Gambar 6. Informasi Request Protocol DNS

Gambar 6 menampilkan informasi format header paket data yang berisi protocol DNS. Aktifitas tersebut melakukan query terhadap domain fucebook.xyz. Analisa pada query sebagai tersebut:

a. Flags bernilai 0x100 yang memiliki arti:

1) Tanggapan pesan bernilai 0 berupa query.

2) Opcode menunjukan nilai 000 berupa query.

3) Potongan pesan bernilai 0 artinya not truncated.

4) Pengulangan bernilai 1 artinya do query recursively.

5) Perlindungan bernilai 0 artinya $Z$ reserved.

6) Konfirmasi data bernilai 0 artinya not authenticated data.

b. Questions bernilai 1 .

c. Answer RRs bernilai 0 .

d. Authority RRS bernilai 0 .

e. Additional RRs bernilai 0 .

3. Paket Data Nomor 132

Paket data nomor 132 pada analisa filterisasi DNS merupakan respon dari paket data nomor 129 kepada DNS server dan diperoleh hasil format header DNS seperti Gambar 7. 


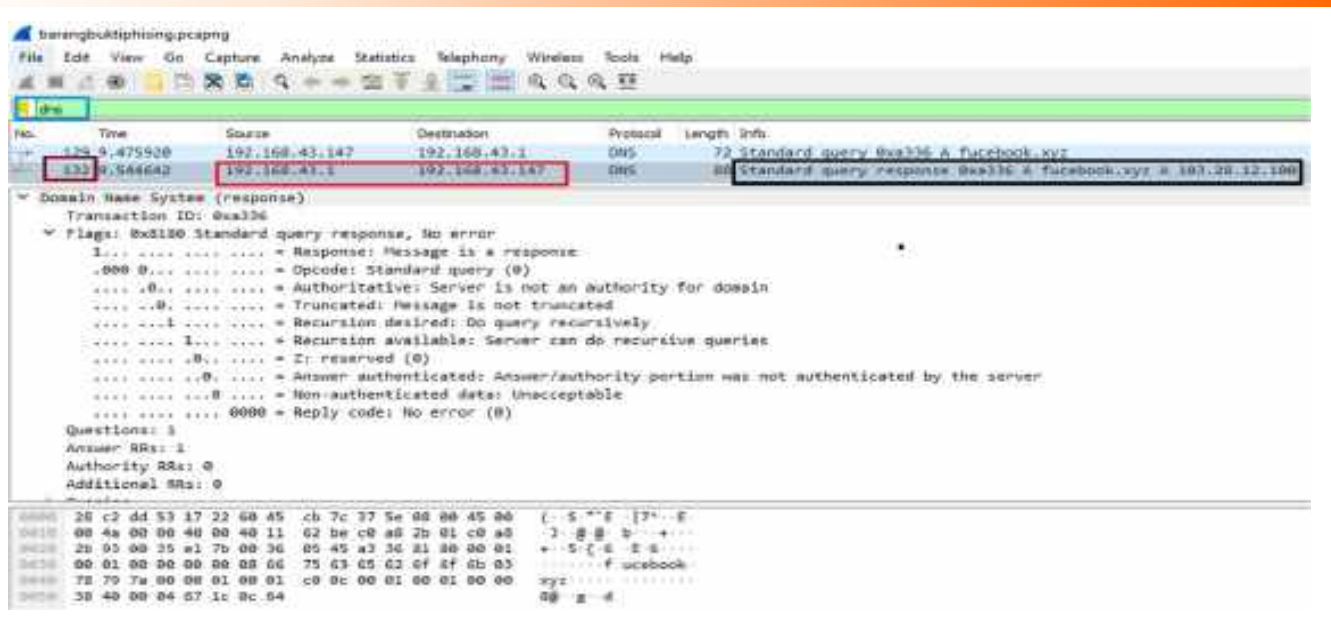

Gambar 7. Informasi Respon DNS Server

Gambar 7 menampilkan informasi hasil respon paket data nomor 129 yang diketahui bahwa respon DNS query fucebook.xyz dengan IP address source 192.168.43.1 dan IP address destination 192.168.43.147. Hasil analisa protocol DNS yang digunakan pelaku dalam melakukan serangan di paket data nomor 132 disimpulkan merupakan paket data protocol DNS.

Setelah diketahui DNS dari web phishing tahap selanjutnya mencari informasi mengenai DNS tersebut menggunakan website https://centralops.net. Setelah mengakses website centralops.net memasukan domain fucebook.xyz pada kolom pencarian domain, maka diperoleh informasi DNS fucebook.xyz seperti Gambar 8.

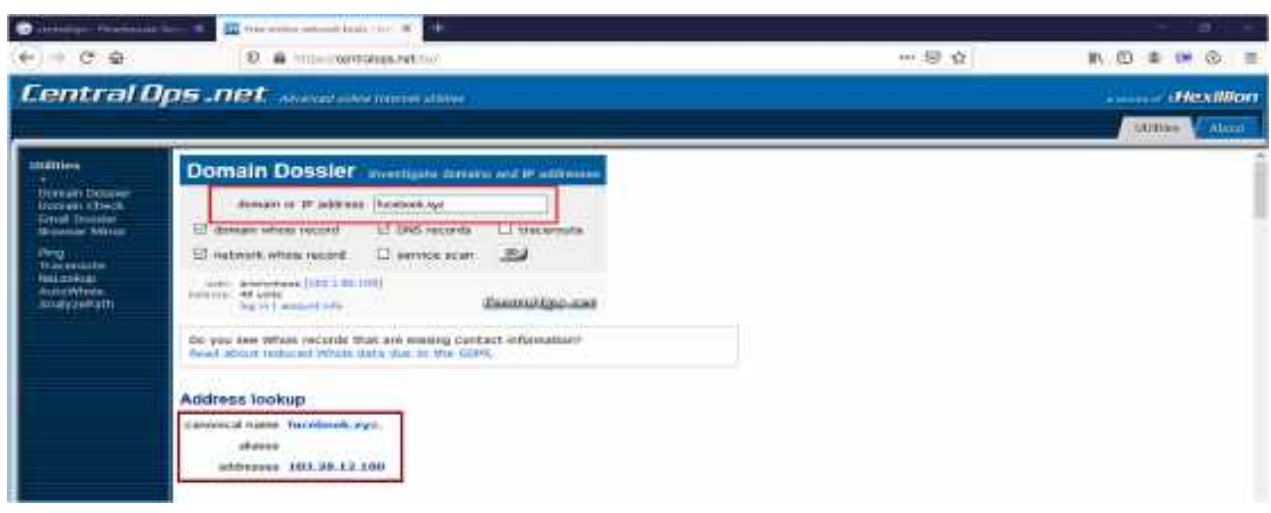

Gambar 8. Informasi IP Address Domain fucebook.xyz

Gambar 8 menampilkan informasi IP address domain fucebook.xyz dengan IP address server 103.28.12.100. Informasi domain whois record yang berhubungan dengan domain fucebook.xyz dan diperoleh informasi lainnya meliputi:

a. Nama domain : fucebook.xyz

b. Pembuatan domain : 30 oktober 2019

c. Organisasi pendaftar: fucebook

d. Provinsi pendaftar : Jawa Tengah

e. Negara pendaftar : Indonesia (ID)

4. Paket Data Nomor 257

Paket data nomor 257 pada analisa filterisasi ip.addr $==103.28 .12 .100$ merupakan record layer handshake protocol "Client Hello" menggunakan protocol TLSv1.2 untuk komunikasi dengan 
membuat sambungan dari client dengan IP address source 192.168.43.147 ke server dengan IP address destination 103.28.12.100, seperti Gambar 9.

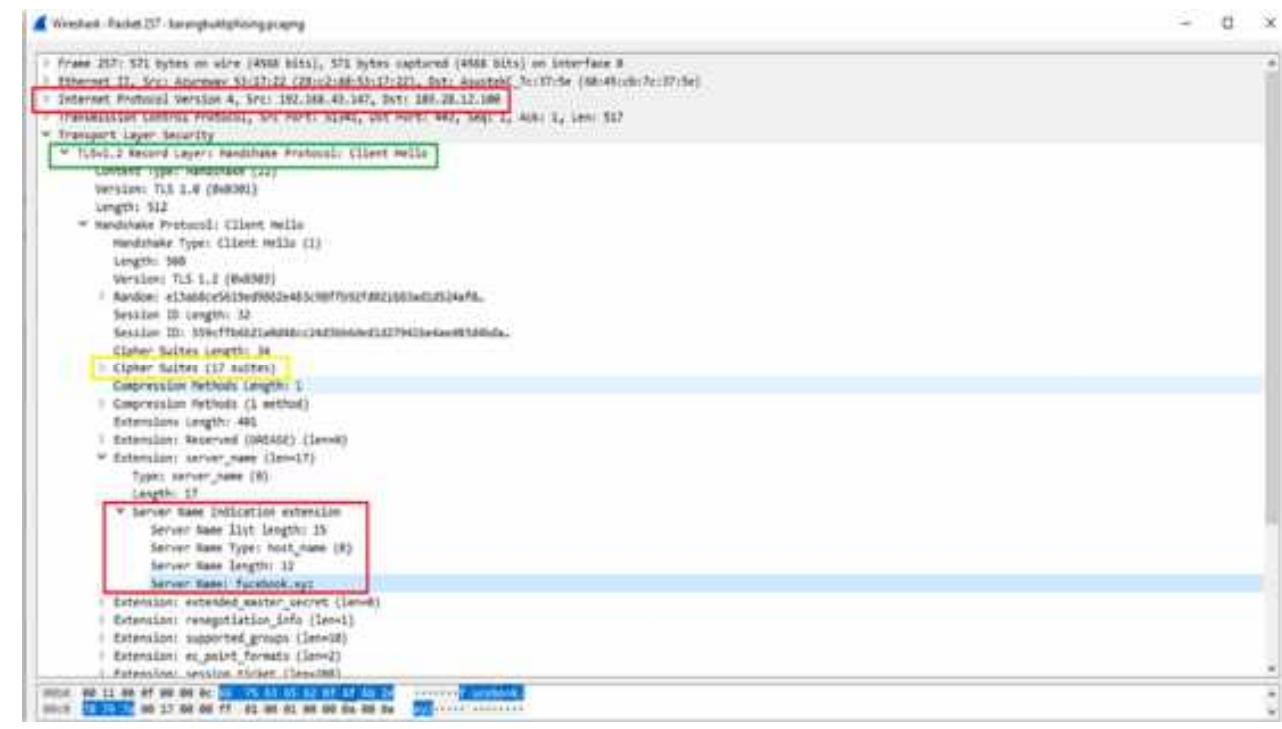

Gambar 9. Informasi Record Layer Handshake Protocol "Client Hello"

Gambar 9 menampilkan pengiriman paket data yang akan dikirim ke DNS dari IP address source 192.168.43.147 dengan mengirim permintaan chIpher suites sebanyak 17 suites yang akan di setujui salah satu suites oleh IP address destination 103.28.12.100 dengan nama server fucebook.xyz yang akan mengamankan komunikasi menggunakan protocol TLSv 1.2.

\section{Paket Data Nomor 259}

Paket data nomor 259 pada analisa filterisasi ip.addr $==103.28 .12 .100$ merupakan record layer handshake protocol "Server Hello" menggunakan protocol TLSv1.2 untuk persetujuan komunikasi yang diminta client IP 192.168.43.147 pada paket data nomor 257 kepada server IP 103.28.12.100, seperti Gambar 10

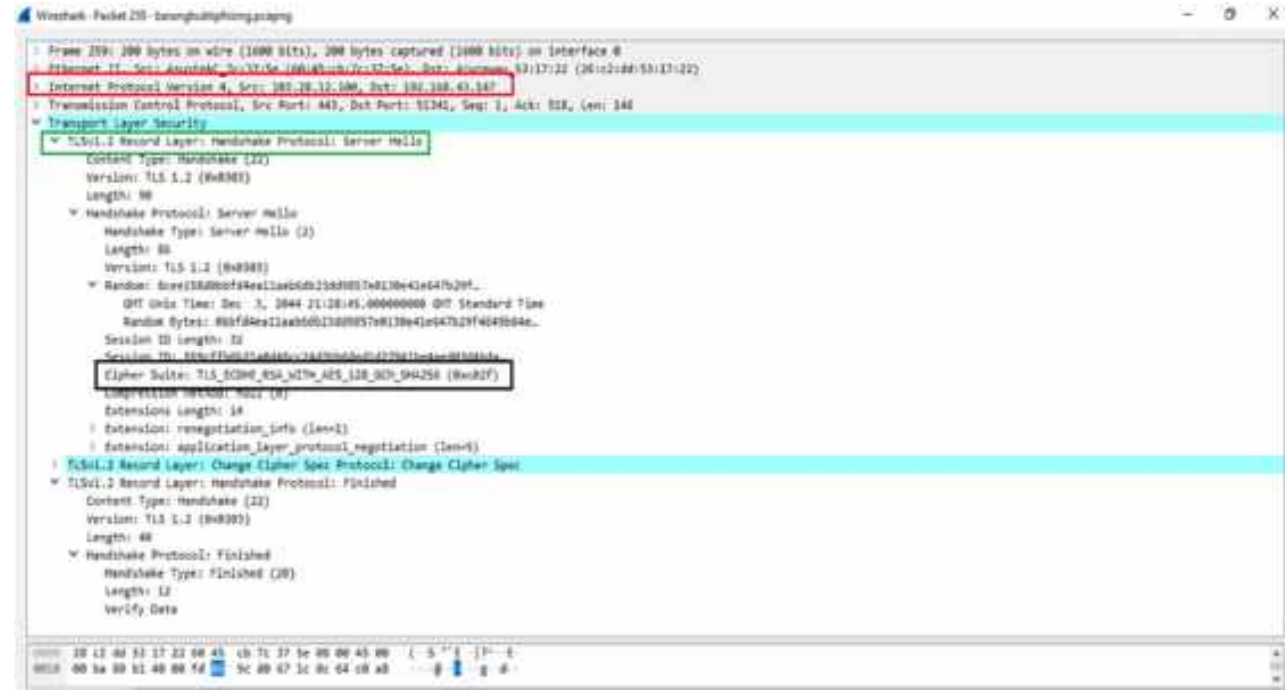

Gambar 10. Informasi Record Layer Handshake Protocol "Server Hello" Gambar 10 menampilkan persetujuan komunikasi dari server dengan IP 103.28.12.100 kepada clien $\begin{array}{lllll}\text { dengan } & I P & 192.168 .43 .147 & \text { menggunakan } & \text { chiper }\end{array}$ TLS_ECDHE_RSA_WITH_AES_128_GCM_SHA256 yang bernilai 0xc02f. 
6. Paket Data Nomor 262

Paket data nomor 262 pada analisa filterisasi http2.header, terlihat IP 192.168.43.147 melakukan request ke IP 103.28.12.100, kemudian IP 192.168.43.147 diarahkan untuk mengakses website tersebut, seperti Gambar 11.

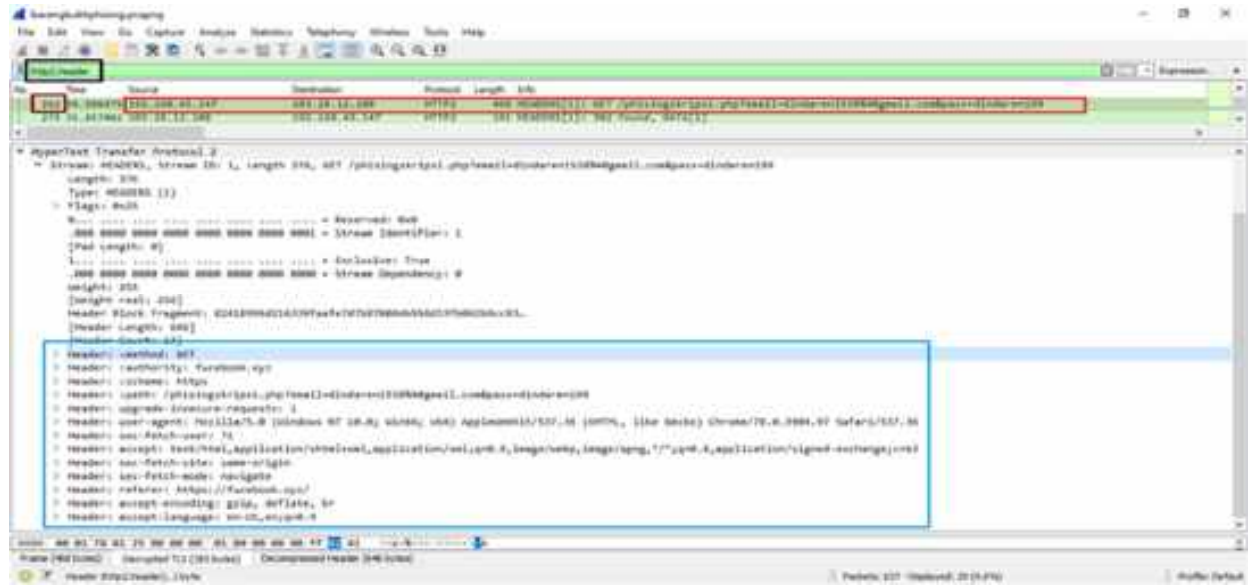

Gambar 11. Informasi Protocol HTTP2 di header Web fucebook.xyz

Gambar 11 menampilkan informasi dari protocol http2 pada header di web fucebook.xyz. Hasil analisis pada paket data nomor 262 di form login web fucebook.xyz, method GET merupakan method yang digunakan phiser di form login untuk pengiriman input data email dan password. Data yang dikirimkan clien dengan IP 192.168.43.147 akan melewati path atau action phisingskripsi.php ke server dengan IP server 103.28.12.100.

\section{Paket Data Nomor 275}

Paket data nomor 275 pada analisa filterisasi http2.header, terlihat IP 103.28.12.100 melakukan respon ke IP 192.168.43.147, kemudian IP 103.28.12.100 memproses data yang di input ke DNS, seperti Gambar 12.

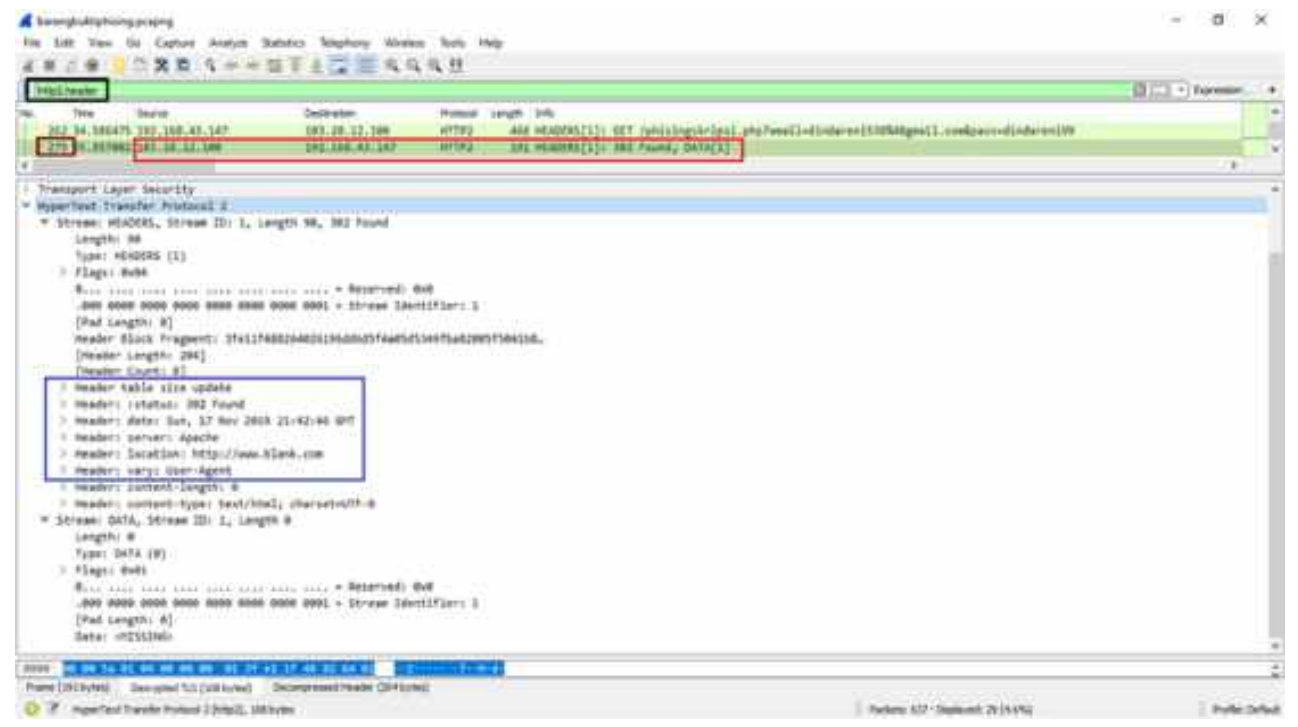

Gambar 12. Informasi Respon dari IP 103.28.12.100

Gambar 4.19 menampilkan respon dari IP 103.28.12.100 ke IP 192.168.43.147. Hasil analisa pada paket nomor 275 terdapat kode status 302 found yang berarti pengalihan dari server dengan IP 
103.28.12.100 ke server baru yang bernama http://www.blank.com dengan IP 199.59.242.153 dengan server apache dan aliran data bernilai 0 .

\subsection{Reporting}

Tahap reporting pada penelitian ini melaporkan hasil analisis barang bukti yang berkaitan dengan laporan korban pada pencurian akun yang telah diskenariokan. Dari file capture barangbuktiphising.pcapng didapatkan hasil analisis. Reporting dari hasil analisis yang telah dilakukan dan disajikan dalam bentuk Tabel 5 .

Tabel 5. Reporting Hasil Analisis File Capture barangbuktiphising.pcapng

\begin{tabular}{|c|c|}
\hline Paket Data & Hasil \\
\hline Paket Data Nomor 148 & $\begin{array}{ll}\text { - } & \text { Pesan e-mail } \\
\text { - } & \text { IP address source : } 192.168 .43 .147 \\
\text { - } & \text { IP address destination : } 74.125 .24 .19 \\
\text { - } & \text { IP: } 209.85 .220 .65 \\
\text { - } & \text { Mail from : Fucebook ( rodalkul09@ to : dindareni538@ gmail.com) } \\
\text { - } & \text { Subject : Please, Sign In Your Account } \\
\text { - } & \text { Isi pesan : https://fucebook.xyz }\end{array}$ \\
\hline $\begin{array}{c}\text { Paket Data Nomor } 129 \\
\text { dan Paket Data Nomor } \\
132\end{array}$ & $\begin{array}{ll}\text { - } & \text { Protocol DNS (Domain Name System) } \\
\text { - } & \text { Host Phishing : fucebook.xyz } \\
\text { - } & \text { IP Address Host Phishing : 103.28.12.100 } \\
\text { - } & \text { IP address source : } 192.168 .43 .147 \\
\text { - } & \text { IP address destination : } 192.168 .43 .1 \\
\text { - } & \text { Prganisasi Pendaftar : fucebook } \\
\text { - } & \text { Negara : Indonesia (ID) } \\
\text { - } & \text { Date : 30 Oktober 2019 } \\
\end{array}$ \\
\hline Paket Data Nomor 257 & $\begin{array}{ll}\text { - } & \text { Protocol TLSv } 1.2 \\
\text { - } & \text { Handshake Protocol : Client Hello } \\
\text { - } & \text { Requests Server Name : fucebook.xyz } \\
\text { - } & \text { IP address source : } 192.168 .43 .147 \text { Request to IP address destination : } \\
& \text { 103.28.12.100 } \\
\text { - } & \text { Send Request Chiper Suites : (17 Suites) } \\
\text { - } & \text { Algorthma : brotli }\end{array}$ \\
\hline Paket Data Nomor 259 & $\begin{array}{ll} & \text { Protocols TLSv.12 } \\
\text { - } & \text { Handshake Protocol : Server Hello } \\
\text { - } & \text { Respon Server Name : fucebook.xyz } \\
\text { - } & \text { IP address source : } 103.28 .12 .100 \text { Respon to IP address destination : } \\
& \text { 192.168.43.147 } \\
\text { - } & \text { Chiper Suites yang dipilih Server : } \\
\text { TLS_ECDHE_RSA_WITH_AES_128_GCM_SHA256 yang bernilai } \\
\text { 0xc02f. }\end{array}$ \\
\hline Paket Data Nomor 262 & $\begin{array}{ll}\text { - } & \text { Protocol http2.header } \\
\text { - } & \text { IP address source : } 192.168 .43 .147 \\
\text { - } & \text { IP address destination : } 103.28 .12 .100 \\
\text { - } & \text { Authority : fucebook.xyz } \\
\text { - } & \text { Scheme : https } \\
\text { - } & \text { Method : GET } \\
\text { - } & \text { Path : phisingskripsi.php?email=dindareni538\%40gmail.com\&pass- } \\
& \text { dindareni99 } \\
\text { - } & \text { Referer : https://fucebook.xyz }\end{array}$ \\
\hline
\end{tabular}

Tabel 5. Reporting Hasil Analisis File Capture barangbuktiphising.pcapng (Lanjutan) 


\begin{tabular}{|l|ll|}
\hline & $\bullet$ & Protocol http2.header \\
& & IP address source : 103.28 .12 .100 Respon to IP address destination : \\
Paket Data Nomor 275 & - & Header Status : 302 Found (Pengalihan) \\
& - & Date $: 17$ november 2019 \\
& - Server : Apache \\
& - Location : http://www.blank.com \\
& - IP Location : 199.59 .242 .153 \\
\hline
\end{tabular}

\section{Kesimpulan}

Menghasilkan barang bukti dari implementasi tahapan metode National Institute Of Standards And Technology (NIST) yaitu collection (pengumpulan data) file capture barangbuktiphising.pcapng didapatkan dari proses rekontruksi serangan pada web phishing, examination (akuisisi data) pemeriksaan nilai hash MD5 pada barang bukti digital, analysis pada barang bukti file capture barangnbuktiphising.pcapng didapatkan tujuh paket data yang berhubungan dengan tindak kejahatan yang dilakukan phiser, reporting (pelaporan) melaporakan barang bukti berupa URL phishing, DNS yang digunakan oleh pelaku, IP address server, IP address destination, identitas penyerang dan email yang menghasilkan informasi tindak kejahatan yang dilakukan phiser. Hasil dari memecah protocols HTTPS secara keseluruhan dengan mendekripsi struktur lalu lintas pada protocols TLSv 1.2 untuk memudahkan investigator dalam menganalisis barang bukti digital. Pada saat investigasi deitemukan celah untuk mendekripsi protocols HTTPS yang digunakan web phishing.

\section{Daftar Pustaka}

[1] D. Andika, "Kejahatan Teknologi Informasi (Cybercrime)," 2017. [Online]. Available: https://www.it-jurnal.com/kejahatan-teknologi-informasi-cybercrime/.

[2] A. Ginanjar, N. Widiyasono, and R. Gunawan, "Web Phising Attack Analysis on ECommerce Service Using Network Forensic Process Method," J. Terap. Teknol. Inf., vol. 2, no. 2, pp. 59-69, 2019.

[3] B. Raharjo, "Sekilas mengenai forensik digital,” J. Sosioteknologi, pp. 384-387, 2013.

[4] S. M. Wisnu Budi , Aan Widayat Kusban, Muhammad, "Analisis Computer Forensic Untuk Mendukung Proses Penyelidikan Dalam Kasus Kejahatan,” p. 12, 2015.

[5] Hakim, "Pengertian Website Menurut Para Ahli I TipsSerbaSerbi." p. PENDIDIKAN, 2004.

[6] A. A. Zabar and F. Novianto, "Keamanan Http Dan Https Berbasis Web Menggunakan Sistem Operasi Kali Linux," J. Ilm. Komput. dan Inform., vol. 69, no. 2, pp. 2089-9033, 2015.

[7] G. Liu, B. Qiu, and L. Wenyin, "Automatic detection of phishing target from phishing webpage," in Proceedings - International Conference on Pattern Recognition, 2010, no. August 2010, pp. 4153-4156.

[8] National Institute Of Standards And Technology U.S Departement of Commerce, "Cybersecurity I NIST," $2019 . \quad$ [Online]. Available: https://www.nist.gov/topics/cybersecurity. [Accessed: 22-May-2019]. 